\title{
THE EFFECT OF LEADER FEATURED MANAGERS ON THE PERFORMANCE AND MOTIVATION OF EMPLOYEES
}

DOI: 10.17261/Pressacademia.2020.1275

PAP- V.11-2020(48)-p.233-235

Kezban Talak

Yeditepe University, Faculty of Economics and Administrative Sciences, Istanbul, Turkey. ktalak@gmail.com, ORCID: 0000-0002-7837-5852

To cite this document

Talak, K. (2020). The effect of leader featured managers on the performance and motivation of employees. PressAcademia Procedia (PAP), V.11, p. 233-235

Permemant link to this document: http://doi.org/10.17261/Pressacademia.2020.1275

Copyright: Published by PressAcademia and limited licensed re-use rights only.

\begin{abstract}
Purpose- Today, business executives play an important role in achieving business goals due to technological developments and increasing competition. In order to achieve the goals, managers must have leadership qualities and employees have value motivation and performance. The purpose of this study is to determine the effects of the leadership qualities of managers on the motivation and performance of employees, taking into account their basic leadership qualities. The main question of the study is what kind of interaction exists between the motivation and work performance of the employees and the leadership characteristics of the managers.

Methodology- Within the scope of the study, the concepts of leadership, management, performance and motivation will be examined in a conceptual framework. In the continuation of the study, the leadership characteristics of the managers will be examined, and then the impact of the managers, who are the main subject of the study, on the performance and motivation of the employees will be examined.

Findings- According to the findings of the study, it was understood that leadership, performance and motivation phenomena interact with each other in businesses and institutions and significantly affect the success of the group in which it is a member. One of the main factors in an organization's employees to achieve the expected performance and desired motivation is determined to work within the body of a manager with leadership qualities. The motivation of the employees increases depending on the leadership characteristics of the managers. It has been confirmed that there is a strong and direct proportionate relationship between leadership or managers and employe es' performances.

Conclusion-. Leadership is at a key position in ensuring employee performance and motivation. In this context, it is concluded that leading managers have a significant effect on employee performance and motivation level. Although it is usual for an employee to see his / her manager as a leader, the fact that the manager has leading characteristics directly affects the performance and motivation of the employee. As the leadership skills of an executive increase, this situation is reflected in the performance of the employee. As a result, not only the goals of the organization, but also the goals of the employees are achieved. The positive atmosphere resulting from the harmony between the administration and the staff will definitely affect the establishment with a positive feedback. In this case, it depends on the management of the enterprises by a leading manager.
\end{abstract}

Keywords: Leadership, management, performance, motivation, staff

JEL Codes: M40, M41, M48.

\section{LIDER ÖZELLIKLI YÖNETICILERIN ÇALIŞANLARIN PERFORMANSI VE MOTIVASYONU ÜZERINE ETKISi}

\section{ÖZET}

Amaç- Günümüzde teknolojik gelişmeler ve artan rekabet nedeniyle, işletme yöneticileri işletme hedeflerine ulaşmada önemli bir role sahiptir. Hedeflere ulaşmak için yöneticilerin liderlik niteliklerine, çalışanların değer motivasyonu ve performansına sahip olması gerekmektedir. Bu çalışmanın amacı, yöneticilerin liderlik niteliklerinin, temel liderlik nitelikleri göz önünde bulundurularak çalışanların motivasyonu ve performansı üzerindeki etkilerini belirlemektir. Çalışmanın temel sorusu çalışanların iş yerlerindeki motivasyonu ve çalışma performansı ile yöneticilerin liderlik özellikleri arasında ne tür bir etkileşim bulunmaktadır. 
Yöntem- Çalışma kapsamında, liderlik, yöneticilik, performans ve motivasyon olgularının kavramsal çerçevede incelenmesi gerçekleştirilecektir. Çalışmanın devamında yöneticilerin liderlik özellikleri incelenecek olup, sonrasında ise çalışmanın ana konusu olan lider özellikli yöneticilerin çalışanlarının performansı ve motivasyonu üzerindeki etkisi incelenecektir. Çalışma nitel araştırma yöntemlerinden literatür taraması yöntemi ile gerçekleştirilecektir.

Bulgular- Çalışmanın bulgularına göre liderlik, performans ve motivasyon olgularının işletmelerde, kurumlarda birbiri ile etkileşim içerisinde olup, üyesi olduğu grubun başarılarını önemli ölçüde etkilediği anlaşılmıştır. Bir kurumun çalışanlarının beklenen performansa ve istenilen motivasyona ulaşmasındaki temel faktörlerden birisi liderlik özelliklerine sahip bir yöneticinin bünyesinde çalışmak olarak belirlenmiştir. Çalışanların motivasyonu yöneticilerin sahip olduğu liderlik özelliklerine bağı olarak artmaktadır. Liderlik veya yöneticiler ile çalışanların performansları arasında güçlü ve doğrudan orantılı bir ilişki olduğu doğrulanmıştır.

Sonuç- Çalışanların performans ve motivasyonunun sağlanmasında liderlik kilit bir konumda yer almaktadır. Bu bağlamda lider özellikli yöneticilerin çalışan performans ve motivasyon düzeyi üzerinde önemli bir etkisi bulunduğu sonucuna varılmıştır. Bir çalışanın yöneticisini lider olarak görmesi olağan bir durum olmakla birlikte, söz konusu yöneticinin lider özelliklerine sahip olması çalışanın per formansını ve motivasyonunu doğrudan etkilemektedir. Bir yöneticinin liderlik becerileri arttıkça bu durum çalışanın performansına önemli ölçüde yansımaktadır. Sonuç olarak, sadece örgütün hedefleri değil, çalışanların hedefleri de gerçekleştirilmektedir. İdare ve personel arasındaki uyumdan kaynaklanan olumlu atmosfer, kuruluşu olumlu bir geri bildirim ile kesinlikle etkileyecektir. Bu durumda işletmelerin lider özellikli bir yönetici tarafından yönetilmesine bağlıdır.

Anahtar Kelimeler: Liderlik, yöneticilik, performans, motivasyon, personel.

JEL Kodları: M40, M41, M48.

\section{KAYNAKÇA}

Artar, M.(1991). İşletmelerde Verimlilik Denetimi, Ölçümü ve Değerlendirme Modelleri, Ankara: MPP Yayınları.

Biçer, T.(1997). “Güçlü İnsan Güçlü Şirket”, Human Resources, Yıl:1 Sayı:7, İstanbul, Mayıs 1997, ss. 12-14.

Büyük Larousse Sözlük ve Ansiklopedisi(1992). Interpress Basın ve Yayıncılık, İstanbul.

Bozkurt, ì.(2004). İletişim Odaklı Pazarlama, 1. Baskı, İstanbul, Mediacat Akademi.

Burns, J.M. (1978) Leadership. New York. Harper \& Row.

Capowski, G.,(1994). “Anatomy of a leader: where are the leader of tomorrow?”, Management Review, 83(3), 10-18.

Casey, BJ, Giedd, JN, and Thomas, KM(2000). Structural and functional brain development and its relation to cognitive development. Biol Psychol 54, ss. 241-257.

Davıs, K.(1984) İşletmede İnsan Davranışı Örgütsel Davranış. Çev. Kemal TOSUN, İstanbul: İ.Ü. Yayın No: 3028.

Deinert, A, Homan, A. C., Boer, D, Voelpel, S. C. \& Guterman, D (2015), "Transformational leadership sub-dimensions and their link to leaders' personality and performance", The Leadership Quarterly , 26, pp. 1095-1120.

Eagly, A. H., Johannesen, M. C., and Engen, M. L. V.(2003), "Transformational, Transactional, and Laissez-Faire Leadership Styles: A Meta-Analysis Comparing Women and Men," Psychological Bulletin, vol. 129, pp. 569-591.

Eeden, R.V., Cilliers, F. and Deventer, V.V.(2005), "Leadership styles and associated personality traits: Support for the conceptualisation of transactional and transformational leadership," South African Journal of Psychology, vol. 38, ss. 253-267.

Eren, E.(2004). Örgütsel Davranış ve Yönetim Psikolojisi, Genişletilmiş 8. Bası, Beta Basım Yayım, İstanbul.

Goleman, D., Boyatzıs, R., McKee, A.(2002) Yeni Liderler,(Çev.:Filiz Nayır, Osman Deniztekin), Varlık Yayınları, İstanbul.

Grady, M.W.(1991). "Performance Measurement, Implementing Strategy”, Management Accounting.

Hall, R.J.ve Lord, R.G.(1995), "Multi-level information-processing explanations of followers" leadership perceptions," The Leadership Quarterly, vol. 6, pp. 265-281, 1995.

Human Synergistics Incorporated. Cascades Survival Situation Participant's Booklet-

sample<http://www. humansynergistics.com/site/index. php?doc175143184>. Human Synergistics Inc., 2003.

İncir, G.(2001)., "Motivasyonu Uyaran Belli Bir Lider Kişilik Yapısından ya da Belli Bir Lider Davranış Biçiminden Söz Edilebilir mi?”, Verimlilik Dergisi, Sa:2, ss.31-46.

Karakaş, B. ve Ak, R.(2003), “Kamu Yönetiminde Performans Yönetimi Önemli midir?”, Kamu Yönetiminde Kalite 3. Ulusal Kongresi Bildirileri, TODAIE Yayınları No: 319, ss. 337-351. 
Kırkpatrıck, S.A. ve Locke, E.A.(1991). “Leadership:Do Traits Matter?”, Academy of Management Review, C.5, Sa:2,ss.48-60.

Kouzes JM, Posner BZ(2002). The Leadership Challenge. San Francisco: Jossey-Bass, ss. 23-29.

Küçük, M. (2008). Eğitim Kurumlarında Yöneticilerin Liderlik Davranışlarının Örgüt İklimi Üzerine ve Eğiticilerin Performansına Etkisi. İstanbul: Beykent Üniversitesi.

Latham, G. P. ve ERNST, C. T.(2006). “Keys to Motivating Tomorrow's Workforce”, Human Resource Management Review, C.16, ss.181-198. 